\title{
High Prevalence Anti-Trypanosoma cruzi Antibodies, among Blood Donors in the State of Puebla, a Non-endemic Area of Mexico
}

\author{
MC Sánchez-Guillén/***, C Barnabé***, JF Guégan***, M Tibayrenc***, \\ M Velásquez-Rojas, J Martínez-Munguía*, H Salgado-Rosas, E Torres-Rasgado, \\ MI Rosas-Ramírez**, R Pérez-Fuentes****/+
}

\begin{abstract}
Laboratorio de Parasitología, Centro de Investigación Biomédica de Oriente *Banco Central de Sangre **Coordinación Delegacional de Epidemiología, Hospital de Especialidades, Centro Médico Nacional Manuel Ávila Camacho, IMSS Puebla, México ***Centre d'Etude sur le Polymorphisme des Micro-organismes, Institute de Recherche pour le Devélopement, Montpellier, France ****Facultad de Medicina, Benemérita Universidad Autónoma de Puebla, Puebla, México
\end{abstract}

Blood transfusion is the second most common transmission route of Chagas disease in many Latin American countries. In Mexico, the prevalence of Chagas disease and impact of transfusion of Trypanosoma cruzi-contaminated blood is not clear. We determined the seropositivity to $\mathrm{T}$. cruzi in a representative random sample, of 2,140 blood donors (1,423 men and 647 women, aged 19-65 years), from a non-endemic state of almost 5 millions of inhabitants by the indirect hemagglutination (IHA) and enzyme linked immunosorbent assay (ELISA) tests using one autochthonous antigen from $\mathrm{T}$. cruzi parasites, which were genetically characterized like TBAR/ME/1997/RyC$V 1$ (T. cruzi I) isolated from a Triatoma barberi specimen collected in the same locality. The seropositivity was up to 8.5\% and 9\% with IHA and ELISA tests, respectively, and up to 7.7\% using both tests in common. We found high seroprevalence in a non-endemic area of Mexico, comparable to endemic countries where the disease occurs, e.g. Brazil (0.7\%), Bolivia (13.7\%) and Argentina (3.5\%). The highest values observed in samples from urban areas, associated to continuous rural emigration and the absence of control in blood donors, suggest unsuspected high risk of transmission of $\mathrm{T}$. cruzi, higher than those reported for infections by blood e.g. hepatitis (0.1\%) and AIDS $(0.1 \%)$ in the same region.

Key words: Chagas disease - seroprevalence - blood donors - antibodies to Trypanosoma cruzi - autochthonous antigens Puebla - Mexico

Chagas disease, caused by the protozoan parasite Trypanosoma cruzi, is now ranked as the most serious parasitic disease of the Americas with an economic impact far outranking the combined effects of the other parasitic diseases such as malaria, schistosomiasis and leishmaniasis (Dias \& Schofield 1999).

Current World Health Organization estimation indicates about 16 to 18 millions people infected with T. cruzi (WHO 1991). Sixty percent of them live in urban areas, and about $50 \%$ are in a latent period. Therefore, since many infected people are potential blood donors, one can expect that a further 100 millions are at risk of contracting the disease (Schmunis 1991, Moncayo 1992, MoraesSouza \& Bordin 1996, Dias \& Schofield 1998).

Following the recent emphasis of public health policies on vector control (Hayes \& Schofield 1990), blood transfusion has now become one of the most significant routes for Chagas disease transmission (Dias 1992, Dodd 1998).

This research was supported by a grant from the FOSIZACONACYT 960802009.

${ }^{+}$Corresponding author and permanent address: Facultad de Medicina, Benemérita Universidad Autónoma de Puebla, 13 Sur 2901, Col. Volcanes, Puebla, México. Fax: +52-222-243.1444. E-mail: rycardoperez@ hotmail.com

Received 10 December 2001

Accepted 26 June 2002
During the past decades, because of the migration from rural to urban areas, while decreasing the rural population exposed to infected vectors (Quintero et al. 1990), Chagas disease became frequent in cities and a health problem in a non endemic countries, where it can be transmitted vertically and by blood transmission (Schumunis 1999a) or organ transplantation (Carvalho et al. 1997). This, thus increases the possibility of alternative pathways to disease contamination.

To date, the status of Chagas disease in Mexico is not clear, although an increasing number of cases of Chagas disease has been reported (Cuartero et al. 1967, VelascoCastrejón \& García 1970, Gloss et al. 1990) since this disease was first recognized in 1940 by Mazzotti. Thus, while the National Seroepidemiological Survey (NSS) (VelascoCastrejón et al. 1992) realized by the official Secretaría de Salud (SSa) showed a prevalence of $1.6 \%$, independent studies carried out, mainly in rural areas, have shown that between $20-30 \%$ of the population was infected by the pathogen (Monteon et al. 1989, Tay et al. 1992). Moreover, positive blood donors have been detected at percentages of $0.2-17 \%$ of infected people (Goldsmith et al. 1978, Trujillo et al. 1993, Ramos-Echevarria et al. 1993, Rangel et al. 1998). This reports highlights the need for a comprehensible evaluation of the prevalence and risk of transmission of T. cruzi in endemic and non-endemic areas in Mexico.

In this work we estimated the prevalence of infection by $T$. cruzi in blood donors living in urban, suburban and rural conditions from a non-endemic area, i.e. the Puebla 
state (Mexico), with almost 5 millions of inhabitants, using two serological tests, i.e. enzyme linked immunosorbent assay (ELISA) and indirect haemagglutination (IHA), as suggested by World Health Organization (WHO 1991), employing an autochthonous antigen attributed to the genetic group T. cruzi I (Momen 1999).

\section{POPULATION AND METHODS}

Study area - The study was carried out in the Puebla state, which is located in the Southeast region of Mexico (Fig. 1), in a valley up to $1,800 \mathrm{~m}$ above the sea level with a warm climate (average annual temperature of $22^{\circ} \mathrm{C}$ ). The population is composed of around 4,579,810 inhabitants; $60 \%$ of them live in rural and suburban conditions, which represents appropriate ecological and socioeconomic conditions for the transmission of Chagas disease.

Studied population - Healthy blood donors, from blood banks of the clinics and hospitals of Instituto Mexicano del Seguro Social (IMSS), Puebla, Mexico, were selected. The criteria included residents of Puebla, aged between $18-65,>50 \mathrm{~kg}$, health clinically and seronegative to Hepatitis B Virus (HBC), Hepatitis C Virus (HCV), Brucella abortus (BrA), Hepatitis B surface antigen (HBsAg), Venereal Disease Research Laboratory (VDRL) and Human Immunodeficiency Virus (HIV) and without history of immunization, transplantation, menstruation, pregnancy or lactation, according to the Technical Norm for Banks of Blood protocol (TNBB). Detection of anti-T. cruzi antibodies by the immunoenzymatic assay ELISA and IHA tests were performed in the Laboratorio de Parasitología, Centro de Investigación Biomédica de Oriente, IMSS, Puebla, México.

In the design of the statistic sample, a stratified model was elaborated. The population was random-stratified considering as total population 4,579,810 inhabitants, distributed in seven regions, denominated Geostatistic Basic Areas (GBA) (National Institute of Geography Information, INEGI), that include the 217 municipalities of the state (Fig. 1). This model represents the urban, suburban and rural populations of the state, according to the socioeconomical, political and cultural levels. The sample size was 2,140 individuals, stratified according the population density in each GBA (Table). The sample was determined with an estimated prevalence for T. cruzi antibodies based on data obtained from the NSS, the desired level of precision for national estimates, with a confidence level of $95 \%$ and a variation coefficient of 0.3 , which corresponded to a minimal expected prevalence of 0.01 (Velasco-Castrejón et al. 1992). The level of precision was allowed to decrease for the different regions. The rural area was characterized by the lacked of sanitary services and presence of poor housing inhabit and coexistence with domestic and peridomestic animals. The suburban population was identified by the poor-housing situated in peripheral area of big cities and lacked of sanitary services and finally the urban population included the individuals, living in an area with total sanitary services.

Serum samples - The sanguine samples from blood donors, were collected of peripherical vein in Vacutainer system, in each selected blood banks of the clinics, hospitals, and Banco Central de Sangre, Hospital de Especialidades, Centro Médico Nacional Manuel Ávila Camacho, IMSS, Puebla. The serum was separated by centrifugation $(1,200 \mathrm{~g}$ for $10 \mathrm{~min})$, it was aliquoted in eppendorf tubes and it was frozen at $-4^{\circ} \mathrm{C}$ and transported to Laboratorio de Parasitología, Centro de Investigación Biomédica de Oriente, IMSS, Puebla where it were stored in freezing $\left(-20^{\circ} \mathrm{C}\right)$ until use.

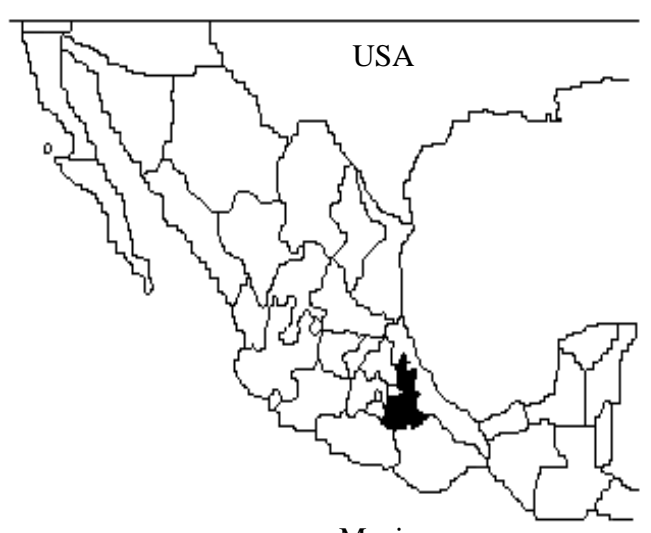

Mexico

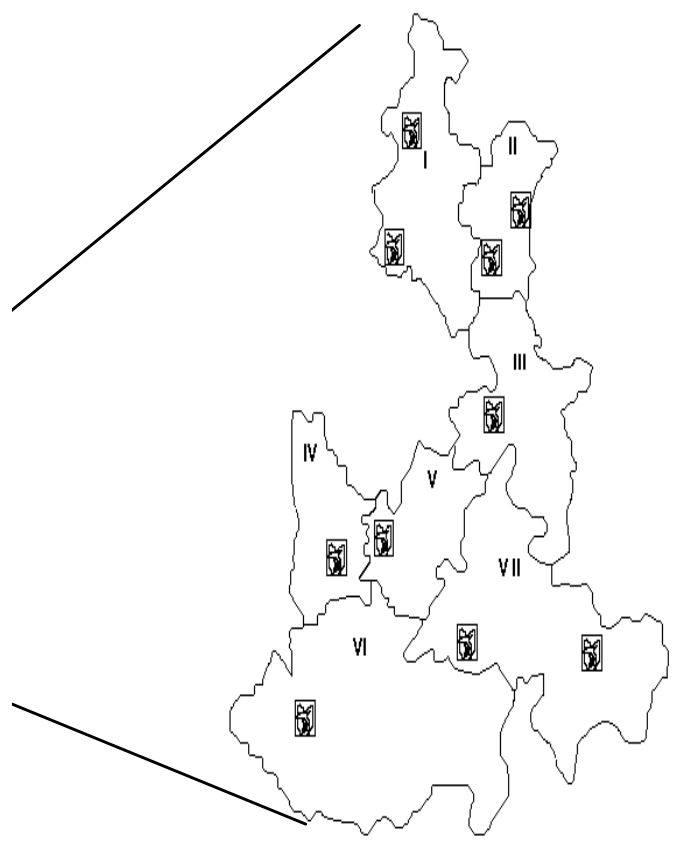

Puebla state

Fig. 1: geographical situation of Puebla state, Mexico, and origin of blood donors considering the GBA (Geostatistics Basic Areas by the INEGI). GAB I: Huauchinango; GAB II: Teziutlán; GAB III: Ciudad Serdán; GAB IV: Cholula; GAB V: Puebla; GAB VI: Izúcar de Matamoros; GAB VII: Tehuacán. 
T. cruzi antigen characterization - T. cruzi parasites, employed as autochthonous antigen, were obtained from a Triatoma barberi specimen collected in the area locality, Puebla, Mexico. The isolated parasites were characterized by Multilocus Enzyme Electrophoresis (MLEE), RAPDs and Biodeme like TBAR/ME/1997/RyC-VI (T. cruzi I).

T. cruzi autochthonous antigen preparation - Total antigen from the Puebla strain RyC-V1 were obtained as previously reported (Pérez-Fuentes et al. 1998). In brief, the parasites (epimastigotes) were cultured and propagated in a liver infusion tryptose medium, supplemented with $10 \%$ fetal calf serum while growing at logarithmic phase was harvested, then sonicated in the presence of protease inhibitors, and spun down to $10,000 \mathrm{~g} \mathrm{x} 30 \mathrm{~min}$ at $4^{\circ} \mathrm{C}$. The supernatant was used as a crude antigenic extract whose protein concentrations, quantified by the method of Lowry were adjusted to $1 \mathrm{mg} / \mathrm{ml}$ and stored at $-70^{\circ} \mathrm{C}$.

Serological characterization - Technique of ELISA Briefly, polystyrene plaques (Dynatech) were sensitized with the crude antigen extract of epimastigotes at a concentration of $100 \mu \mathrm{g} / \mathrm{ml}$ in carbonates buffer $\mathrm{pH} 9.5$ and blocked with bovine fetal serum to $1 \%$ in PBS-Tween 20 $(0.01 \%)$. The blood donors and controls sera were diluted $1: 100$ and incubated by $1 \mathrm{~h}$, washed with PBS. It was employed conjugated human anti-IgG coupled to radish peroxidase, the colorimetric reaction was developed with ortophenilen-diamino and peroxide of hydrogen. The reaction was stopped and it was reading at $490 \mathrm{~nm}$ in ELISA's reader.

Technique of IHA - The sensitization of the blood red cells was required for this assay. Ram erythrocytes was used at a concentration of $2.5 \%$ in buffer of phosphate $\mathrm{pH} 7.2$, they were mixed with tannic acid at a dilution of 1:60,000 and they were sensitized with autochthonous antigen from $T$. cruzi at $37^{\circ} \mathrm{C}$ for $20 \mathrm{~min}$, they were washed themselves with PBS pH 7.2 and adjusted at a concentration of $0.2 \mathrm{mg} / \mathrm{ml}$. The problem sera at dilutions $1: 8,1: 32$ and 1:64 were incubated by $2 \mathrm{~h}$ to room temperature. The identification of the antibodies was determined by the agglutination presence in the bottom of the wells of the plate. It was considered the title of 1:8 as infection and $1: 32$ as confirmatory. All samples were analyzed by triplicate and repeated twice.

Positive and negative controls were included in each test. A positive result was defined as titer $>1: 32$ for the IHA test and $>0.200$ for the ELISA. In both assays we employed the autochthonous T. cruzi antigens. Soluble epimastigote antigen was prepared as previously described.

\section{RESULTS}

A total of 2,140 random blood samples of the seven areas of the Puebla were evaluated for anti T. cruzi antibodies using ELISA and IHA tests. All subjects were $>18$ years of age, weight $>50 \mathrm{~kg}$, clinically healthy, and were residents from rural, suburban and urban areas in Puebla. The average age of the individuals was 32 years old ranging from 19 to 50 years with a female:male ratio of 1:3. All donors were seronegative for $\mathrm{HBC}, \mathrm{HCV},(\mathrm{HBsAg}), \mathrm{BrA}$, VDRL and HIV, and all of them fulfilled criteria to Technical Norm of Bank of Blood. Due to the lack of serologic "gold standard" for the diagnostic of Chagas disease, the sera employed in the evaluation were characterized by both matched IHA and ELISA tests. In each case, we tested for antibodies against $T$. cruzi using epimastigotes of autochthonous antigens. Of the 2,140 serum samples analyzed, 194 (9.1\%) showed antibodies against T. cruzi with ELISA and 182 (8.5\%) for IHA techniques, respectively. However, we considered as carriers of $T$. cruzi antibodies, the 166 (7.7\%) individuals ( 127 men and 39 women, mean age $36.8 \pm 16.4$ ), that were seropositive to both assays, i.e. ELISA and IHA, according to WHO recommendations (1991).

Then, the samples were divided (Fig. 2) considering the distribution of seropositive blood donors for T. cruzi antibodies by both ELISA and IHA tests and according to the stratification in seven district regions proposed by the INEGI.

Table illustrates the distribution of seropositive samples, including positive, negative and discordant results, by studied areas. Prevalence rates were different between urban, suburban and rural origins for patients

TABLE

Distribution of IHA and ELISA test seropositive blood donors according to their geographical origin and total samples

\begin{tabular}{lcccccccc}
\hline GBA $^{a}$ & Total population $^{b}$ & Sample $^{c}$ & IHA & ELISA & $(+)^{d}$ & $\left(_{-}\right)^{e}$ & Discordant $^{f}$ Mean age $^{g}$ \\
\hline I & 609,670 & 285 & 16 & 18 & 15 & 266 & 4 & $42 \pm 15$ \\
II & 446,840 & 208 & 14 & 1 & 14 & 187 & 7 & $37 \pm 14$ \\
III & 346,335 & 162 & 11 & 15 & 10 & 146 & 6 & $38 \pm 17$ \\
IV & 700,804 & 328 & 21 & 18 & 18 & 307 & 3 & $33 \pm 18$ \\
V & $1,360,557$ & 636 & 86 & 84 & 80 & 546 & 10 & $36 \pm 19$ \\
VI & 370,077 & 173 & 6 & 5 & 4 & 166 & 3 & $35 \pm 16$ \\
VII & 744,827 & 348 & 28 & 33 & 25 & 312 & 11 & $37 \pm 16$ \\
\hline Total & $4,525,110$ & 2,140 & 182 & 194 & 166 & 1930 & 44 & \\
\hline
\end{tabular}

$a$ : Puebla state is divided in seven Geostatistics Basic Areas (GBA) in order to make economical and geographic analysis; $b$ : total population from each GBA; $c$ : representative randomized sample from each GBA; $d$ : true positives using both assays; $e$ : true negatives using both assays; $f$ : assay results differing between the two serological analysis; $g$ : mean age of seropositives from each GBA; IHA: indirect hemagglutination. The positive samples were at 1:32 dilution; ELISA test: the cut value was 0.044 \pm 0.009 O.D. All cases were using the same dilution 1:100. 
tested by IHA (Fisher's exact test with correction, $\mathrm{p}=$ $\left.10^{-5}\right)$, by ELISA $\left(\mathrm{p}=2.4 \times 10^{-4}\right)$ and by both tests $\left(\mathrm{p}=10^{-}\right.$ $\left.{ }^{4}\right)$. In addition, comparison were also significant between urban and suburban plus rural when plotted together by IHA $\left(\mathrm{p}=10^{-5}\right)$, by ELISA $\left(\mathrm{p}=10^{-5}\right)$ and by both tests $(\mathrm{p}=$ $\left.10^{-6}\right)$.

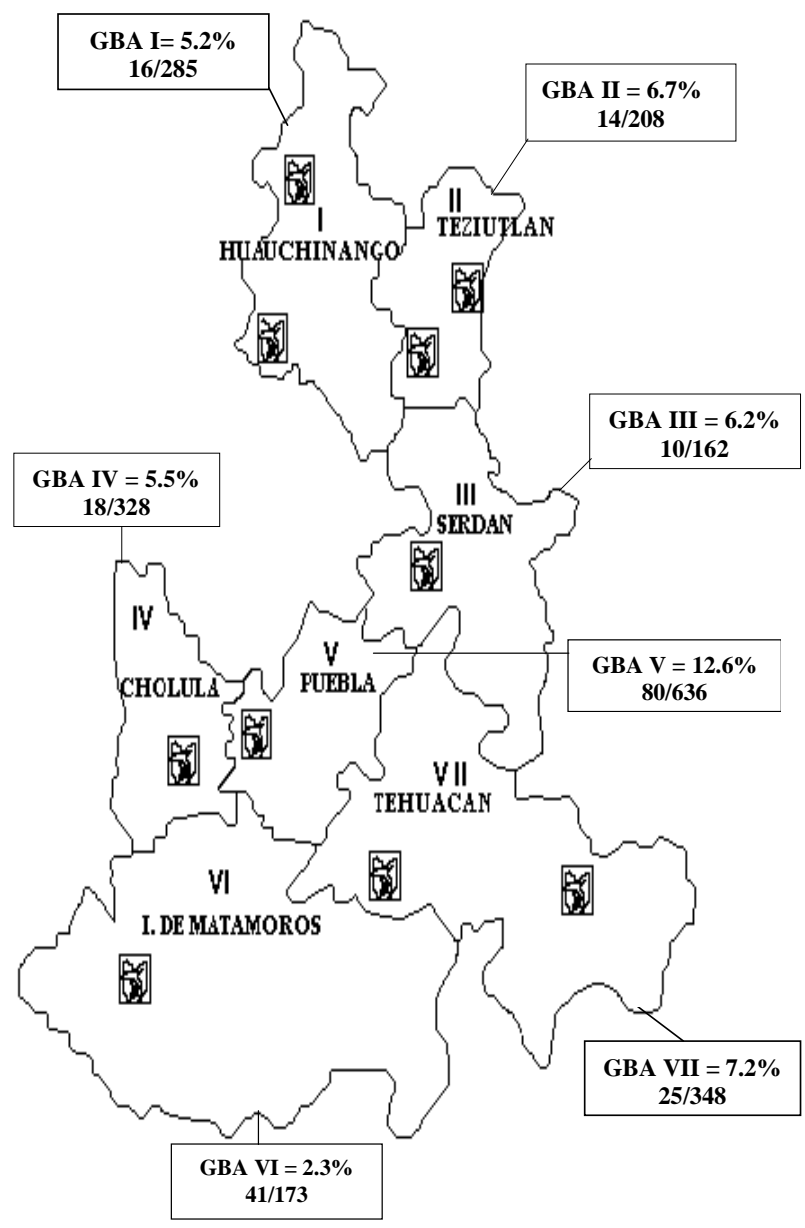

Fig. 2: distribution of blood donors seropositives to antibodies against Trypanosoma cruzi by both IHA and ELISA tests. The results show the absolute values and \% of seropositives according to the population density in each Geostatistcs Basic Areas (GBA).

\section{DISCUSSION}

While in many Latin American countries, Chagas serological tests are mandatory for all blood donors, in Chile (Ministerio da Saúde 1993) and in Mexico (Guzmán-Bracho et al. 1998) this measure is applied only in endemic areas. Furthermore, screening in Mexico is not routinely done in all endemic states (Schmunis 1999b).

The data presented in this work are relevant because they clearly establish the seroprevalence of $T$. cruzi antibodies in blood donors, and provide information on the prevalence of the infection in Mexico, where the information regarding the importance of the transmission of Chagas disease is either limited or under estimated.
This study shows that the seroprevalence found in blood donors of a non-endemic area of Mexico (7.7\%), i.e. the Puebla state, is relatively high, and comparable to those found in endemic states of others countries. These findings strongly contrast with the NSS in Mexico carried out in 1987, and published in 1992, which showed a low prevalence of $1.6 \%$. These differences may be in part attributed to the fact that this last study was performed with statistics specifically designed for the characterization of urban transmissible diseases, such as AIDS, hepatitis, but not for rural transmissible diseases such as Chagas disease (Velasco-Castrejón et al. 1992). Besides, our findings (7.7\%) contrast with the more recent study carried out by the official SSa, that showed only $1.5 \%$ of national prevalence and specifically $1.8 \%$ from Puebla (Guzmán-Bracho et al. 1998). The discrepancy could be explained in part by the serologic tests employed (we used both ELISA and IHA assays), strain of the parasite used in the antigen preparation (autochthonous antigen), and mainly, by the size (random sample) and characteristic of analyzed population. Thus, in this work was performed in 64,969 blood donors, where approximately 850,000 donations are done yearly, including samples from 18 of the 32 Mexican states, and the study did not rely on any specific statistics.

The antibody based immunoassay play a relevant role as diagnostic tool because of their high sensitivities. In the particular case of Chagas disease, no serologic "gold" standard exists, since detection of $T$. cruzi-specific antibodies depends on many factors. Nevertheless, IFA is the most commonly used serologic test for Chagas disease and, as result, is widely accepted as the gold standard (Ferreira \& Moraes de Avila 1995). Recent reports show that in-house IFA and in-house ELISA were highly concordant (Oelemann et al. 1998). Like is suggested by Organización Panamericana de la Salud (OPS), IHA is a screening technique while ELISA or IFA is for confirmatory diagnosis with a higher specificity than IHA. In this work, in total agreement with the OPS recommendations that mandatory serology must be implemented in all countries where T. cruzi is endemic by using at least two serological tests (OPAS 1998), we used two independent techniques, i.e. in-house IHA and in-house ELISA with the same antigen, the last assay presented a higher specificity to Chagas disease detection (Pérez-Fuentes et al. 1998).

However, few countries use more than one test for blood donor screening (Schmunis 1999). A study carried out in 1998 in Cuernavaca (town of Morelos, Mexico) showed a seropositivity in blood donors of $17 \%$, using a commercial ELISA kit in consecutive blood samples from 318 donors (Rangel et al. 1998).

Our findings can be explained in part by the kind of antigen we have used in serologic tests, further studies have suggested that the specificity of different methods depends on the selection of an adequate antigen (Mendes et al. 1997), considering that T. cruzi is polymorphic, and different parasite strains circulate in different areas (Dias 1992). Then, genetic characterization of T. cruzi parasites have shown that Mexican stocks belonging to T. cruzi I and are closely related to each other (Bosseno et al. 2002). 
In Mexico, most studies have been performed using $T$. cruzi antigens extracted from strains originating from other geographical origins, mainly South America, that show different genotypes (Bucio et al. 1999).

Previously, we have shown that assays utilizing commercial antigens from other countries are lesser sensitive than using T. cruzi authocthonous antigen in the diagnostic of Chagas diseases (Pérez-Fuentes et al. 1998). Recently this finding was demonstrated by other authors (Sánchez et al. 2001).

The specificity of our analysis was to use autochthonous antigens from local $T$. cruzi strains isolated in the same area and characterized as $T$. cruzi I, could be naturally reflect locally adapted host immune response against T. cruzi natural clones circulating in the area.

In Mexico, the infection by $T$. cruzi is mainly silent. Thus, like in most countries of Latin America, Chagas disease has become an urban disease, due to the migration of people from endemic areas to the cities (Moraes-Souza 1999). In this work, although all of individuals were resident of the region in study, the prevalence rate for T. cruzi antibodies found in the blood donors of urban origin, i.e. Puebla (V Area), were twice higher than those of rural regions, where the identification of T. barberi, the insect vector and the conditions for natural infection and transmission exist (unpublished data, Pérez-Fuentes $\mathrm{R}$ et al.). This could be explained by the migration of infected people from rural to urban areas as Puebla, capital city, due to the poor socioeconomic as in many Latin American countries. This could be suggest that urban transmission is now overcoming the classical rural transmission.

Many recent reports (Guzmán-Bracho et al. 1998, Dumontiel 1999, Schmunis 1999) show the need for a comprehensive evaluation of the prevalence and distribution of Chagas disease in Mexico. In the present study, the identification of substantial prevalence of seropositive blood donors to $T$. cruzi suggests the existence of a high risk of contamination by blood transfusion. As others have proposed, the routine programs of serologic screening with immunological techniques with high sensibility and specificity definition, i.e. T. cruzi antigens extracted from local strains, are urgently needed and applied. This should be done in all areas, including those that are considered as non-endemic.

The last years, fortunately the situation has improved in Mexico. The ministry of Health has approved a law about screening for anti-T.cruzi antibodies in the whole territory. Also, epidemiological surveillance and vector control programs have started to inform regulation (Guzmán-Bracho 2001).

Our results confirm that blood transfusion is an important parameter in Chagas disease transmission in Mexico, besides the classical vectorial transmission. Vector control therefore must be completed by adequate screening measures in all Mexican transfusion centers.

\section{ACKNOWLEDGEMENTS}

To the personal from Clínicas Comunitarias and Banco Central de Sangre del Centro Médico Nacional Manuel Ávila Camacho del Instituto Mexicano del Seguro Social for the facilities for this work; to the staff of U.M.R. 9926 C.N.R.S.-I.R.D. in Montpellier, France for their invitation to come for a postdoctoral fellowship of RPF financed by CONACyT (00208) and MCSG financed by IMSS.

\section{REFERENCES}

Bosseno MF, Barnabé C, Magallón-Gastélum E, Lozano-Kasten F, Ramsey J, Espinoza B, Breniére SF 2002. Predominance of Trypanosoma cruzi lineage I in Mexico. J Clin Microbiol 40: 627-632.

Bucio MI, Cabrera M, Segura EL, Zenteno E, Salazar-Schettino M 1999. Identification of immunodominant antigens in Mexican strains of Trypanosoma cruzi. Immunol Invest 28: $257-268$

Carvalho MF, de Franco MF, Soares VA 1997. Amastigotes forms of Trypanosoma cruzi detected in a renal allograft. Rev Inst Med Trop São Paulo 39: 223-226.

Cuartero L, Ponce D, Recco R 1967. Cinco nuevos casos de enfermedad de Chagas en Zacatecas y Jalisco, en la Republica Mexicana. Rev Invest Salud Publica Mex 27: 29-32.

Dias JC 1992. Epidemiology of Chagas disease. In S Wendel, Z Brener, ME Camargo, A Rassi (eds), Chagas Disease (American Trypanosomiasis): its Impact on Transfusion and Clinical Medicine, International Society of Blood Transfusion, São Paulo, p. 49-80.

Dias JC, Schofield CJ 1998. Controle da transmissão transfusional da doença de Chagas na iniciativa de cone sul. Rev Soc Bras Med Trop 31: 373-383.

Dias JC, Schofield CJ 1999. The evolution of Chagas disease (American trypanosomiasis). Control after 90 years since Carlos Chagas discovery. Mem Inst Oswaldo Cruz 94 (Suppl. I): 103-121.

Dodd RY 1998. Transmission of parasites by blood transfusion. Vox Sang 74 (Suppl. 2): 161-163.

Dumontiel E 2001. Update on Chagas disease in Mexico. Salud Publica Mex 41: 359.

Ferreira AW, Moraes de Avila SL 1995. Laboratory diagnosis of Chagas heart disease. São Paulo Med J/RPM 113: 767-771.

Gloss G, Barrera MR, Monteon VM, Reyes PA 1990. Tripanosomiasis americana y cardiopatia chagasica cronica en el Instituto Nacional de Cardiologia Ignacio Chavez. Arch Inst Cardiol Mex 60: 261-266.

Goldsmith RS, Zarate R, Kagan I, Cedeño-Ferreira J, GalindoVasconcelos M, Antonio-Paz E 1978. El potencial de la transmision en la enfermedad de Chagas por transfusion sanguinea: hallazgos serologicos entre donadores en el estado de Oaxaca. Salud Publica Mex 20: 439-444.

Guzman-Bracho C 2001. Epidemiology of Chagas disease in Mexico: an update. Trends Parasitol 17: 372-376.

Guzmán-Bracho C, García-García L, Floriani-Verdugo J, Guerrero-Martínez S, Torres-Cosme M, Ramírez-Melgar C, Velasco-Castrejón O 1998. Riesgo de transmisión de Trypanosoma cruzi por transfusión de sangre en Mexico. Rev Panam Salud Pub 4: 94-99.

Hayes RJ, Schofield CJ 1990. Estimación de las tasas de incidencia de infecciones y parasitosis crónicas en base a su prevalencia: la enfermedad de Chagas en América Latina. Bol Oficina Sanit Panam 108: 308-316.

Mendes RP, Hoshino-Shimizu S, Moura da Silva AM, Mota I, Heredia RA, Luquetti AO, Leser PG 1997. Serological diagnosis of Chagas disease: a potential confirmatory assay using preserved protein antigens of Trypanosoma cruzi. J Clin Microbiol 35: 1829-1834.

Ministerio da Saúde, Brasil 1990-1991 1993. Coordenação de sangue e hemoderivados. Relatório de atividades: Anexo IX. Ministerio de Salud, Chile 1990-1991. Diagnostico de la situacion de los bancos de sangre y medicina transfusional en Chile. Ser Inf Tecnicos: 14. 
Momen H 1999. Taxonomy of Trypanosoma cruzi: commentary on characterization and nomenclature. Mem Inst Oswaldo Cruz 94: 181-184.

Moncayo A 1992. Chagas disease: epidemiology and prospects for interruption of transmission in the Americas. World Health Stat Q 45: 276-279.

Monteón VM, Sosa T, Reyes PA 1989. Serological test for American trypanosomiasis: a comparative study. Rev Latinoam Microbiol 31: 35.

Moraes-Souza H 1999. Chagas infection transmission control: situation of transfusional transmission in Brazil and other countries of Latin America. Mem Inst Oswaldo Cruz 94 (Suppl. I): 419-423.

Moraes-Souza H, Bordin JO 1996. Strategies for prevention of transfusion associated Chagas disease. Transfus Med Rev 10: $161-170$.

OPAS-Organizacion Panamericana de la Salud 1998. Situación de los bancos de sangre en América Latina. 1996: marcadores serológicos para enfermedades transmisibles a donantes de sangre. Bol Epidemiol 19: 11-13.

Oelemann WM, Teixeira MG, Da Costa GV, Borges-Pereira J, De Castro JA, Rodríguez-Coura J, Peralta JM 1998. Evaluation of three comercial enzyme-linked immunosorbent assays for diagnosis of Chagas disease. J Clin Microbiol 36: 2423-2427.

Pérez-Fuentes R, Sánchez-Guillén MC, González-Álvarez C, Monteón VM, Reyes PA, Rosales-Encina JL 1998. Humoral nitric oxide levels and antibody immune response of symptomatic and indeterminate Chagas disease patients to commercial and autochthonous Trypanosoma cruzi antigen. Am J Trop Med Hyg 58: 715-720.

Quintero ZT, Troncoso MC, Arnesi N, Boggio G, Sánchez S 1990. Comportamientos migratorios en dadores de sangre y las probabilidades de transmitirla por medio de la transfusión. Bol Chil Parasitol 24: 88-93.

Ramos-Echevarria AA, Monteón-Padilla VM, Reyes-López PA
1993. Detección de anticuerpos contra Trypanosoma cruzi en donadores de sangre. Salud Publica Mex 35: 56-64.

Rangel H, Gatica R, Ramos C 1998. Detection of antibodies against Trypanosoma cruzi in donors from a blood bank in Cuernavaca, Morelos, Mexico. Arch Med Res 29: 79-82.

Sánchez B, Monteón V, Reyes PA, Espinoza B 2001. Standardization of micro-enzyme-linked immunosorbent assay (ELISA) and western blot for detection of Trypanosoma cruzi antibodies using extracts from mexican strains as antigens. Arch Med Res 32: 382-388.

Schmunis GA 1991. Trypanosoma cruzi, the etiologic agent of Chagas disease: status in the blood supply in endemic and non endemic countries. Transfusion 31: 547-557.

Schmunis GA 1999a. Prevention of transfusional Trypanosoma cruzi infection in Latin America. Mem Inst Oswaldo Cruz. 94 (Suppl. I): 93-101.

Schmunis, GA 1999b. Risk of Chagas disease through transfusions in the Americans. Medicina (B Aires) 59 (Suppl. 2): 125-134.

Tay J, Schenone H, Sánchez JT, Robert L 1992. Estado actual de los conocimientos sobre la enfermedad de Chagas en la Republica Mexicana. Bol Chil Parasitol 47: 43-53.

Trujillo F, Lozano F, Soto M, Hernández R 1993. Prevalencia de infeccion a Trypanosoma cruzi en donadores de sangre en el estado de Jalisco, Mexico. Rev Soc Bras Med Trop 26: 89.

Velasco-Castrejón O, García L 1970. Estudio clínico y epidemiológico de un nuevo caso humano de enfermedad de Chagas en la Republica Mexicana. Prensa Med Mex 35: 438.

Velasco-Castrejón O, Valdespino JL, Tapia-Conyer R, Salvatierra B, Guzmán-Bracho C, Magos C, Llausas A, Gutiérrez G, Sepúlveda J 1992. Seroepidemiología de la enfermedad de Chagas en Mexico. Salud Publica Mex 34: 186-196.

WHO-World Health Organization 1991. Control of Chagas disease. Report of a WHO Expert Committee, WHO Technical Report Series 811: 95. 